\title{
O brincar e as relações de gênero: reflexões de crianças e docentes
}

Playing and gender relations: reflections of children and teachers

\author{
Cássia Cristina Furlan* \\ Universidade Estadual de Maringá \\ Verônica Regina Müller** \\ Universidade Estadual de Maringá
}

Resumo A pesquisa buscou analisar o que crianças e docentes pensavam a respeito do brincar e as questões de gênero. No total, participaram das intervenções com o jogo 18 crianças, sendo 10 meninos e 8 meninas, e 13 professoras, todos/as da cidade de Sarandi/PR. Os dizeres das crianças acerca das representações de gênero foram conseguidos a partir da aplicação do jogo Trilhas da Diversidade, dentro do Projeto Brincadeiras e, com as docentes, no ambiente escolar, utilizando-se do jogo, por meio da técnica de grupo focal. Partindo dos episódios, conversas e brincadeiras, compreendemos a diversidade de identidades e papéis que crianças e docentes constroem e assumem. Tanto em relação às crianças como às docentes, vários foram os momentos e situações em que o conflito se estabeleceu, advindo daí uma reflexão crítica.

PALAVRAS-CHAVE: Brincar; Gênero; Trilhas da Diversidade.

Abstract The research sought to examine what children and teachers thought about playing and gender issues. In total, 18 children participated in the interventions with the game, 10 boys and 8 girls, and 13 teachers, all of them from the city of Sarandi / PR. The children' words about gender representations were achieved from the application of the game named Trails of Diversity, within the Play Project and, with the teachers, in a school setting, using the game through the focus group technique. Through the episodes, conversations and plays, we understand the diversity of identities and roles that children and teachers construct and assume. Both for the children as the teachers, there were several moments and situations in which the conflict settled, arising there from critical reflection.

KEYWORDS: To play; Gender; Trails of Diversity. 


\section{Introdução}

As culturas infantis de hoje não são iguais às culturas infantis de ontem, pois se manifestam em outro tempo e espaço, com outro formato e conteúdo (BARBOSA, 2007). Uma parte característica da cultura infantil é o brincar, condição de aprendizagem e de sociabilidade.

Nesse sentido, a pesquisa tratou de aspectos específicos que se relacionam ao brincar e às diferentes construções e reconstruções de sentidos que as crianças fazem, e também as docentes, no que tange às questões de gênero ${ }^{1}$. No total, participaram das intervenções com o jogo 18 crianças, sendo 10 meninos e 8 meninas, e 13 professoras, todos/as da cidade de Sarandi/PR. Durante toda a pesquisa, a principal motivação para a formulação de pensamentos a determinadas questões, tanto para as crianças quanto para as docentes, foi o uso do jogo Trilhas da Diversidade ${ }^{2}$. Esse jogo permitiu chegar mais perto do universolúdico da criança e, assim, possibilitou-nos entender um pouco das diferentes realidades e experiências que cercam o mundo infantil com o qual estávamos brincando, ao mesmo tempo em que o pesquisávamos. Nas intervenções com as crianças alguns relatórios foram produzidos pelas/os educadoras/es presentes nas intervenções, a respeito das suas principais impressões, servindo também como fonte de análises. Com as docentes, realizamos a técnica de grupo focal (NETO et. al., 2002), com o desenvolvimento do Trilhas e, posteriormente, formação específica dentro das questões de gênero e sexualidade.

Para tanto, partimos das respostas das crianças e das docentes, na tentativa de desvendar o que produz certa diferenciação em relação a brincadeiras e brinquedos propostos para cada gênero, entendendo que a cultura lúdica dispõe de certa autonomia, mas que só pode ser entendida em interdependência com a cultura global de uma sociedade específica. E neste sentido, a criança adquire e constrói sua cultura lúdica brincando; ela é o conjunto de sua experiência lúdica acumulada. Entretanto, é também na cultura lúdica que aspectos da cultura geral adquirem traços específicos (BROUGÈRE, 2002; 2008), por vezes reconstruindo valores e representações da cultura geral.

\section{"[...] Ela vai brincar com brincadeira de menina"}

O brincar, segundo Barbosa (2007), serve para organizar e dar sentido à vida diária das crianças. $\mathrm{O}$ brincar não é um momento em que as crianças param de viver e sentir a sociedade e os seus constrangimentos, mas um momento de construção dessas vidas sociais, com consequências que podem advir da intervenção dos/as adultos/as e da interação com outras crianças, construindo-se ordens sociais inclusivas e/ ou exclusivas.

Ao trabalharmos o jogo Trilhas da Diversidade, um dos pontos que foram abordados se referia a brinquedos e brincadeiras generificados, ou seja, considerados próprios para meninos ou meninas. A professora no grupo focal dá o exemplo de um aluno que só gostava de brincar com menina, com "brinquedos de menina" e usar "roupa de menina". 
MARGARIDA ${ }^{3}$ : Dava a bonequinha azul, ele não, eu quero o rosa prof. [...] mas quando eu trabalhava com ele era só brincadeira de menina, ele escondia debaixo da mesa pra brincar com as meninas. De boneca. Ele queria ser a mamãe na brincadeira, ele não queria ser o papai. [...] Então, assim, ele sempre se colocava no lugar da mulher, e não no lugar do homem. [...] então, agora uma amiga minha é professora dele, [...] ela disse que agora... assim... acabou, ele brinca com os meninos... eu acredito assim, que a criança, ela escolhe o caminho desde pequeno, só que eu acho que se voce influenciar a fazer isso, a continuar fazendo isso, ele vai, ele vai pra outro caminho. Ele vai gostar sempre da brincadeira de menina.. querer ser mulher. Agora, eu acho que tem que assim, tratar de alguma forma e depois, futuramente, se ele quiser escolher esse caminho, é opção dele, mas, não desde criança, deixar assim?! [...].

Nessa primeira fala, podemos observar que para a docente há a diferenciação de brinquedos e brincadeiras pelo critério do sexo/gênero, pois, para ela, certas brincadeiras são características de menina, como o caso da boneca. Outro aspecto que nos chama atenção é o exposto em relação ao menino que só queria brincar com meninas. Para a professora e familiares, as atitudes do menino caracterizam uma pessoa do gênero feminino e, portanto, os responsáveis devem tomar alguma providência para que a criança não continue "fazendo isso", para não ir "pra outro caminho".

$\mathrm{Na}$ perspectiva da fala apresentada, nos deparamos com normalizações a respeito do gênero, como se o gênero decorresse de um sexo previamente estabelecido. Segundo Louro (2007), o termo gênero ou gender passou a ser usado a partir das feministas anglo-saxãs para mostrar a distinção do termo sexo ou sex. A autora afirma que foi visando rejeitar o determinismo biológico implícito no uso de termos como sexo ou diferença sexual que as feministas acentuaram, através da linguagem, "o caráter fundamentalmente social das distinções baseadas no sexo” (SCOTT, 1995, p.72). Dessa forma, o conceito passa a exigir que se pense de modo plural, acentuando que os projetos e representações sobre mulheres e homens são diversos.

Para ela,

Outra autora que corrobora com essas discussões é Judith Butler (2003).

[...] se o gênero são os significados culturais assumidos pelo corpo sexuado, não se pode dizer que ele decorra de um sexo desta ou daquela maneira. Levada a seu limite lógico, a distinção sexo/gênero sugere uma descontinuidade radical entre corpos sexuados e gêneros culturalmente construídos. Supondo por um momento a estabilidade do sexo binário, não decorre daí que a construção de "homens" aplique-se exclusivamente a corpos masculinos, ou que o termo "mulheres" interprete somente corpos femininos. [...] Quando o status construído do gênero é teorizado como radicalmente independente do sexo, o próprio gênero se torna um artifício flutuante, com a consequência de que homem e masculino podem, com igual facilidade, significar tanto um corpo feminino como um masculino, e mulher e feminino, tanto um corpo masculino como um feminino (BUTLER, 2003, p. 26). 
O gênero não deve ser concebido como meramente uma inscrição cultural de significado num sexo previamente dado. Segundo Hall (1997), a cultura é um dos elementos mais dinâmicos e imprevisíveis da mudança histórica no novo milênio. Nossas identidades são formadas culturalmente. Essas complexas formas de construções estão firmemente ligadas à questão cultural.

Na situação apresentada pelo Trilhas da Diversidade, questionamos as crianças sobre a seguinte situação: "Uma menina brinca de carrinho e futebol e a chamam de machona. É correto?", uma delas respondeu: "Valdir: não. Por quê? Valdir: Ah... porque muié também joga bola". No relatório (2011), referente à prática no Projeto Brincadeiras, segundo as educadoras, "as crianças responderam que não tem problema brincar juntos, e a Kauany afirmou que menina também pode ser boa jogadora de futebol". Em outra pergunta sobre o futebol, o relatório (2011) expõe: “Na hora de escolher o time de futebol, os meninos não deixaram as meninas serem escolhidas, no mesmo momento. A Giovana, indignada, disse que não estava certo. $\mathrm{E}$, em seguida reforçou: Giovana: ah, eu não quero menino mandando em mim não".

Então perguntamos às professoras o que acreditavam ser a resposta das crianças quanto a ser correto chamarem uma menina de machona porque brinca de carrinho e futebol. Para AZALÉIA, "não (com sinal de negação gestual). Eles vão dizer que às vezes isso é correto. A criança vai responder, mas a gente tem uma concep̧ço que não, que não é o brinquedo que vai mudar uma criança". E outra professora complementa:

ROSA: é, porque a escola prega isso né... não é o brinquedo que vai mudar uma... [...] a minha filha andando na rua com o pai, acho uma carreta velha, só a parte da frente. Ela pediu para o pai dela que reconstruisse a parte de trás porque ela queria aquele carrinho. [...] E ela fala assim, olha quando eu crescer eu vou ser motorista. Eu vou pilotar moto. [...] mas, os brinquedos dela, foram brinquedos direcionados a menina. Porque o que minha mãe me ensinou era brinquedos DE menina. E eu ensinei pra minha filha brinquedos DE menina.

Seguiram-se algumas discussões e exposição de opiniões, sendo a mesma professora questionada por suas colegas sobre a opção da filha quanto à carreta:

AZALÉIA: nem por isso ela deixou de escolher a carreta pra brincar.

ROSA: não... não, ela não deixou de escolher a carreta, ela não deixou de jogar futebol com o pai, ela não deixou de soltar pipa.

[...]

ROSA: não, mas o dia de soltar pipa, o pai dela fez uma pipa pra ele, fez uma pipa pra ela, vamos soltar. Mas, a hora que ela vai brincar comigo, ela vai brincar com brincadeira de menina. Nós vamos brincar de Barbie.

\section{Por quê?}

ROSA: porque eu gosto de brincar de Barbie. E ela também... eu acho...

(risos)...

É importante notar que a criança, mesmo com certas influências direcionando-a para brinquedos que "condigam" com seu 'gênero', por vezes se comporta contrariamente às normas e padrões impostos por sua mãe. Borba $(2005$, p.51) afirma 
que as crianças se encontram em um mundo adulto estruturado por relações que organizam suas vidas cotidianas e suas relações com o mundo, e nesse contexto vão constituindo suas identidades como crianças e membros de um grupo social. Entretanto, elas não devem ser vistas como sujeitos passivos que apenas incorporam a cultura adulta que lhes é imposta, "[...] mas como sujeitos que, interagindo com esse mundo, criam formas próprias de compreensão e de ação”, como ressaltamos nas escolhas da criança em questão.

Quando apresentamos a resposta das crianças para as professoras, em relação a possibilidade de meninas jogarem futebol, a ROSA disse: “também joga bola. Nós temos a estrela do futebol ai, a Marta".

Percebemos nessa situação apresentada pelo jogo Trilhas da Diversidade, que algumas crianças e também algumas professoras entendem ser a prática do futebol não exclusiva dos meninos, ou seja, ela é uma prática permitida para ambos os gêneros. Entretanto, podemos observar que a mãe - e professora - sente-se incomodada com certas escolhas da filha, visto que para ela, oriunda de uma educação tradicional, há certa separação no que se refere aos gêneros e suas possibilidades e escolhas. Esse fato se verifica em um questionamento feito pela professora no decorrer do curso, referindo-se à escolha de sua filha pelo futebol. ROSA: "Eu tenho medo das curvinhas dela vira curvinha de homem (risos). [...] ah, ela chega com a canela roxa, ela é delicada. E ai eu tenho medo de ficar com a perna grossa, sabe perna de homem".

Há, nesta perspectiva apresentada pela docente, a continuidade das representações de corpo condizentes com um gênero, em que características femininas devem ser prezadas na mulher, como afirma Louro (2000), pois o feminino é positivo se encontrado na mulher, e o mesmo pode-se dizer do masculino em homens, do contrário, torna-se algo fora do padrão esperado e, por isso, indesejado.

Algumas professoras defenderam a prática do futebol, questionando a posição da professora quanto a certas "curvinhas" masculinizadas. Então a ROSA diz: "ah, eu assisti uma entrevista da Marta, olha ela, meu Deus do céu, ela é bonita, mas, assim, você viu assim...". BEGÔNIA: "você acha que ela tem um jeito meio masculina? Masculinizada?" ROSA: "eu achei sim...”. Esta posição reafirma um argumento de Goellner (2006, p.1) sobre a aproximação, por vezes recorrente, "[...] entre o futebol e a masculinização da mulher e naturalização de uma representação de feminilidade que estabelece uma relação linear e imperativa entre mulher, feminilidade e beleza", representação esta que só pode ser compreendida a partir de uma visão essencialista dos gêneros que não permite visualizar as multiplicidades contidas em cada polo.

Ao partirmos para um aprofundamento da questão referente ao futebol e a outras atividades que pudessem ser caracterizadas como associadas a um dos gêneros, surgem algumas restrições feitas pelas docentes e também pelas crianças, o que se percebe quando invertemos a pergunta, colocando o menino na situação principal. $\mathrm{Na}$ proposição: "Meninos que não gostam de futebol e brincam de boneca: a) devem ser considerados "mariquinhas"; b) têm o direito de brincar com aquilo de que gostam e serem respeitados por isso; c) merecem ser alvo de gozação, pois boneca é coisa de 
menina". Maria respondeu: "b. Por quê? Maria: Ah, porque brinquedo foi feito pra todos". Já Paulo respondeu: "Não, meninos não podem brincar de boneca, isso é coisa de menina. E menina não pode brincar de carrinho, porque é coisa de menino isso".

No relatório fica explícita a diferenciação de gênero quando Giovani se expressa: "O Giovani (5 [anos]) era o único que não aceitava algumas respostas, para ele meninos devem brincar com coisas vistas como de meninos, ou seja, carrinho, cor azul e para ele é inaceitável a ideia de meninos brincarem de bonecas, entre outros" (RELATÓRIO, 2011). Outro momento, ainda apontado pelas educadoras, refere-se à permissão para que meninas brinquem com brinquedos socialmente considerados de meninos. Entretanto, no caso dos meninos há um preconceito maior, associado às noções de masculinidade.

Entre as crianças, percebemos que há diversas maneiras de pensar em relação aos brinquedos e seus gêneros, o que nos remete a um ponto explicitado por Wenetz (2012), afirmando existir uma mobilidade na classificação de brincadeiras das crianças, ou seja, entre as falas/discursos e a prática das atividades, pois algumas crianças afirmam que os brinquedos são feitos para todos e, portanto, permitidos para todos, como observamos no início das explanações. Entretanto, outras crianças, como Giovani e Paulo demonstram seu entendimento sobre a existência de certas masculinidades que não "permitem" a utilização, por meninos, de brinquedos considerados femininos e vice-versa.

Pesquisas (GOMES; CUNHA, (2011); PENTEADO; MENDONÇA, (2009); RIBEIRO, (2006) realizadas sobre brincadeiras de meninos e meninas têm observado diferentes aspectos no que concerne às relações de gênero: a influência do brincar para que a criança possa transcender as fronteiras delimitadas pela estrutura binária de gênero; a manutenção de certas brincadeiras diferenciadas para cada gênero, como também a flexibilidade de algumas identidades, assumindo múltiplas formas de masculinidade e feminilidade nas práticas cotidianas; e, ainda, em algumas populações, observam-se as diferenciações de gênero profundamente enraizadas na cultura local, em que se qualificam os comportamentos pertinentes aos grupos de meninos e de meninas, exigindo condutas sociais e sexuais específicas. Para Ribeiro (2006), entre as próprias crianças da sua pesquisa, existe a manutenção do ser homem e do ser mulher pautada não só no aspecto biológico, mas em concepções socialmente apreendidas na família e no sistema das relações em que vivem.

A partir das pesquisas apreciadas, verificamos haver em cada lugar e em cada cultura, diferenças quanto às representações que se têm das características femininas e masculinas, as quais muitas vezes são transmitidas para as crianças, observadas também nos momentos do brincar. Tratamos desse aspecto, em nosso estudo, abordando um contexto específico em que opiniões e realidades são perpetuadas, vivenciadas e mesmo reconstruídas pelas crianças.

Essas questões podem ser observadas nas falas de várias professoras, e também das crianças, quando se referiam a comportamentos e práticas comumente classificadas como femininas ou masculinas, verificando-se, entretanto, a possibilidade de transgressões, principalmente cogitadas por meninas. Em alguns momentos de in- 
tervenção com as professoras, elas demonstraram certo desconforto quando citavam exemplos de meninos e meninas que partilhavam de experiências e modos de vivências não condizentes com a prática cotidiana delas (professoras).

Realizamos a seguinte afirmação, partindo do Trilhas da Diversidade com as crianças: "Os meninos e as meninas que moram ao lado da sua casa brincam juntos". Para Vitória há diferenciação em relação a brincadeiras. Vitória: "as meninas brincam de boneca, os moleque brincam de carrinho".

Para esta criança, meninos e meninas possuem brincadeiras próprias para cada gênero. Na situação posta, parece haver certa segurança, por parte de meninas e de meninos em relação à classificação das brincadeiras. Wenetz (2005) afirma que as crianças não duvidam de que é natural e normal algumas brincadeiras serem só para meninas e outras só para meninos, pois, por estar tão naturalizado esse sentido para algumas crianças, não produz um estranhamento. Sendo assim, podemos retomar Foucault (1997), quando fala sobre os efeitos de verdade de um discurso, em que este se torna tão natural a ponto de ser tomado como uma verdade. Entretanto, também é observado que as crianças admitem algumas misturas, mais do que as professoras, no que se refere à transposição dos gêneros nas brincadeiras.

Dessa maneira, quando perguntamos às professoras o que elas achavam da proposição referente a meninos e meninas brincarem juntos, elas disseram:

BEGÔNIA: está certo. [...] eles brincam muito juntos. Menina com menino.

ROSA: oh, você sabe que eu sou egoísta né. Eu falo pro meu povo de Deus, as minhas meninas tão ficando mocinhas, então, eu... eu, dependendo da brincadeira, eu falo assim que eu não quero. Porque elas, agora, agora que tá a formação dos mamilos, tá começando... então, tá a flor da pele, eu não posso deixar o negócio pega ali não... então... se deixa pega... eu pego, eu falo pras meninas assim ó: vocês vão brincar no recreio, mas vocês vão brincar comportados, tá. Vocês, elas tão, algumas tão trazendo até livro de literatura pra ler no recreio, não sei se vocês já perceberam? São as minhas alunas tá. Os meninos estão trazendo as cartinhas pra estar brincando entre eles, $e$ as mocinhas elas conversam entre elas, sei lá... mas, elas não ficam correndo, não ficam pulando, saltitando de jeito nenbum. E... na rua, por exemplo, eu vou pegar na rua de casa, eu moro aqui no Sarandi, bem ali na periferia. E, na rua da minha casa, as mães elas não deixam as meninas brincarem com os meninos, as mães não deixam as meninas irem na casa das outras meninas, eu não deixo a minha filha brincar com as outras meninas da rua. As outras mães também não. E os meninos, eles jogam bola na frente da minha casa, [...] eles não convidam as meninas pra brincar [...].

$\mathrm{Na}$ fala da professora ROSA, um aspecto explicitado diz respeito a existência de uma estreita ligação entre a infância e o lugar onde ela é vivenciada. As crianças, ao se apropriarem e ao se criarem em um determinado lugar, criam diferentes histórias em suas diferentes geografias, influenciadas também pela cultura a sua volta. Há uma diferenciação quanto à educação de meninos e meninas em determinadas regiões, como notamos nas pesquisas apresentadas (GOMES; CUNHA, 2011; PENTEADO; MENDONÇA, 2009; RIBEIRO, 2006; WURDIG, 2007). 
Há uma distinção maior entre as crianças por gênero, à proporção do aumento da idade, intensificando-se o grau de separação (WÜRDIG, 2007; PEREIRA; MOURÃO, 2005; PENTEADO; MENDONÇA, 2009). E essa caracterização apresenta-se nas regras incutidas pela escola e na educação imposta pelas famílias, mesmo que por vezes, na mídia e em outros meios, haja certa defesa da igualdade na educação de meninos e meninas. Pereira e Mourão (2005) verificaram também que algumas professoras reforçam, mesmo que inconscientemente, a separação das crianças por sexo. Até mesmo o fato de não discutirem com os alunos sobre a separação entre os universos masculino e feminino nos rituais da escola, não interferindo nessa ordem estabelecida, já seria um indicativo da pouca atenção que dão ao assunto. Ao contrário, como se vê no caso explicitado pela nossa pesquisa, por vezes, a professora é a pessoa que ajuda a incutir essa separação e diferenciação na educação das crianças.

Embora não possamos generalizar, relacionando determinadas situações a todas as docentes e famílias, não podemos também negar a recorrência do pensamento da separação por gêneros em diversas crianças do projeto e em algumas professoras. Porém, é importante registrar que as crianças não brincam exclusivamente segregadas. Grupos mistos são menos frequentes, porém não raros. Em relação à segregação, Silva et. al. (2004) encontraram um resultado bastante revelador da conduta de meninos e meninas: a significativa penetração das meninas nos grupos de meninos e em suas brincadeiras. Esses autores argumentam que a penetração das meninas no espaço masculino não se dá apenas pela pouca disponibilidade de parceiros (elas mesmas poderiam se segregar em grupos menores), mas sim por resistência e pressão das meninas que invadem e se apropriam da "cultura masculina", diminuindo a distância entre os dois gêneros, como observamos na fala da professora MARGARIDA:

\begin{abstract}
[...] eles [os meninos] ficam jogando bola em frente a minha casa, mas não deixa nenhuma menina lá, só tem minha prima que tá lá. Que ela gosta de brincar com os meninos (risos), ela é danadinha. Mas a minha vó não gosta, porque assim, pela idade, ela fala assim que menina tem que se por lugar dela, entẫo ela chega lá pra brincar, e jâ diz assim: você não tem vergonha não, só você de menina, você não se coloca no seu lugar menina [...].
\end{abstract}

No estudo de Fiaes et. al. (2010) - realizado com sujeitos de 1 a 18 anos de idade em parques públicos de Salvador - as autoras mostram que meninas entre quatro e seis anos parecem dispor da mesma oportunidade para brincar na rua que os meninos. Após essa faixa, e marcadamente a partir dos 13 anos, pode ser visto um maior "recolhimento" das meninas às suas casas, fato que explicam como resultante de certo envolvimento das meninas com trabalhos domésticos e da crença popular de que a rua é mais perigosa para as meninas.

Silva et. al. (2004) notaram que a participação de meninas e meninos em brincadeiras consideradas predominantemente de um dos gêneros parece estar acontecendo, mas entre os meninos esta penetração nas brincadeiras mais "femininas" acontece em menor quantidade. As autoras afirmam que a rua é um espaço de ocupação sexualmente diferenciado, no qual elas encontraram tanto diferenças na participação 
por gênero quanto na diversidade das culturas lúdicas. Podemos questionar, na nossa pesquisa, sobre a diferença da participação das crianças na rua como implicação das noções de diferenciação sexual, pois a rua continua sendo um espaço de domínio masculino, em variadas situações. No espaço público parece haver necessidade de vigilância constante dos/as adultos/as sobre as crianças, para que nada saia do controle, como a professora ROSA expõe: "[... ó, eu não vou dizer que minha filha brinca só com menina também não[...]. Só que o negócio não pode sair do nosso controle".

Felipe (1999, p.169) entende que "os tipos de jogos, brinquedos e brincadeiras que oportunizamos a meninos e meninas, a utilização dos espaços que permitimos a um e a outro, são alguns dos exemplos de como os indivíduos vão se constituindo", muitas vezes, presos a normas e padrões que separam "destinos" para cada criança, de acordo com seu gênero.

A pesquisa de Straub (2002) desenvolve-se sobre os modos como acontece um disciplinamento do corpo infantil através das brincadeiras, observando como estas são parte de um grande contexto que captura as crianças e o caráter produtivo do poder ao produzir um determinado modo de ser criança. Aborda também a forma pela qual a vigilância, a sanção normalizadora e o controle do tempo, do espaço e dos gestos operam nas brincadeiras na construção da criança.

A sanção normalizadora opera, segundo Foucault (2000), para ajustar os comportamentos individuais, os quais devem ocorrer dentro de padrões que produzam os sujeitos normais. Afirma que "lugares determinados se definem para satisfazer não só a necessidade de vigiar, de romper comunicações perigosas, mas também de criar um espaço útil” (FOUCAULT, 2000, p. 123). Essa vigilância constante que se dá, como afirma a professora ROSA, para que as crianças não fujam do controle, tem reflexos diferentes na brincadeira dos meninos e das meninas.

Entretanto, percebemos certa resistência também por parte de algumas crianças, como mostra o relatório de uma educadora, e que nos surpreendeu positivamente:

Ao adentrarmos na escola, fomos brincar de bola, ele [criança] começou a fazer embaixadinha. Fiquei encantada com aqueles pezinhos sujos, fazendo tantas embaixadinhas, então pedi para que ele me ensinasse, ele tentou, mas não teve jeito. Então falei para ele: Porque será que eu não consigo ser boa igual a você? Ele então retrucou, é porque você tem o pé muito grande! (RELATÓRIO, 2011).

Segundo Finco (2003), a variedade dos brinquedos e as diversas opções de brincadeiras podem favorecer a ocupação dos espaços por meninas e meninos indiscriminadamente. Os brinquedos são compreendidos como elementos culturais, próprios de significados e de um enredo social, e as crianças estão a todo o momento recriando novos significados para esses elementos culturais. Quando há a categorização dos brinquedos como sendo femininos ou masculinos, por exemplo, essas categorizações são construções criadas por adultos/as. Relacionar gênero e infância permite que possamos enxergar as múltiplas formas de ser menino e de ser menina ,que as categorizações não nos deixam ver. 


\section{Algumas considerações}

No decorrer da pesquisa, um diálogo se estabeleceu entre as pesquisadoras, as crianças e as professoras, agregando reflexões e conhecimentos. Esse caminho foi estimulado por ações espontâneas e intencionais de aproximação dos pensamentos e representações apresentadas pelas crianças e pelas professoras, a partir da experiência com o jogo Trilhas da Diversidade.

Por meio dos episódios, conversas e brincadeiras, compreendemos a diversidade de identidades e papéis que crianças e docentes constroem e assumem. Contudo, não há consenso, e isso nos traz esperança. No decorrer de toda a pesquisa, tanto em relação às crianças como às docentes, vários foram os momentos e situações em que o conflito se estabeleceu, advindo daí uma reflexão crítica. O que nos interessa é mostrar que uma pequena porção de dúvida que tenhamos inserido na maneira de pensar de cada um e de cada uma, já pode ser o começo de uma mudança de perspectiva rumo ao respeito às diferentes formas de ser, agir e se construir diante do mundo.

A pesquisa faz parte de uma pesquisa mais ampla que problematiza, a partir das discussões com o jogo, também a falta de formação e preparo docente para o trato com essas questões, observadas nas falas durante a exposição. Crenças religiosas também foram abordadas, por mostrarem-se presentes nos discursos produzidos pelas professoras ao longo da proposta de intervenção. Para além do término deste texto, precisamos enfatizar a necessidade constante de problematização das relações de gênero e sexualidade, pois os resultados nos mostram como ainda estão presentes estereótipos e discriminações que deturpam significados e produzem exclusões.

A experiência com o jogo nos confirma que o brinquedo pode ser uma forma muito eficaz de aproximação dos adultos às ideias das crianças; e que o brinquedo pode ser também uma forma eficaz de nos aproximarmos das ideias dos adultos; e mais, que o mesmo brinquedo pode servir para gerações tão diferentes. As crianças se revelaram não ser um resultado automático da cultura, nem do que as professoras ensinam. $\mathrm{O}$ imaginário infantil é um fator que deve ser valorizado.

\section{Referências}

BARBOSA, C. A. V. B. Dos corpos nascidos aos sexos construídos: as representações de género das crianças em jardins-de-infância. 2007. 223 f. Dissertação (Mestrado) - Universidade do Minho, Instituto de Estudos da Criança, 2007.

BORBA, Â. M. Culturas da infância nos espaços-tempos do brincar: um estudo com crianças de 4-6 anos em instituição publica de educação infantil. 2005. 298 f. Tese (Doutorado) - Universidade Federal Fluminense, Faculdade de Educação, 2005a.

Infância e cultura nos tempos contemporâneos: um contexto de múltiplas relações. Teias, Rio de Janeiro, v.6, p.11-12, jan/dez 2005b.

BROUGÈRE, G. A criança e a cultura lúdica. In: KISHIMOTO, T. M. (Org.). O brincar e suas teorias. São Paulo: Pioneira Thompson Learning, 2002, p. 19-32.

. Brinquedo e cultura. 7 ed. São Paulo: Cortez, 2008.

BUTLER, J. Problemas de gênero: feminismo e subversão de identidades. Rio de Janeiro: Civilização Brasileira, 2003. 
FELIPE, J. Entre tias e tiazinhas: pedagogias culturais em circulação. In: HERON DA SILVA, L. (Org.). Qual conhecimento? Qual currículo? Petrópolis: Vozes, 1999.

FINCO, D. Relações de gênero nas brincadeiras de meninos e meninas na educação infantil. Pro-Posições, Campinas, v. 14, n. 3, p. 89-101, set./dez. 2003.

FIAES, C. S.; et. al. Gênero e Brincadeira em Parquinhos Públicos de Salvador (BA). Interação em Psicologia, Curitiba, v. 14, n. 1, p. 31-41, 2010.

FOUCAULT, M. Vigiar e punir: o nascimento da prisão. 22. ed. Petrópolis: Vozes, 2000.

Microfísica do Poder. 11ª ed., Rio de Janeiro: Graal, 1997. Disponível em: <http:// filoesco.unb.br/foucault/>. Acesso em: 01 maio 2008.

GOELLNER, S. V. Na "Pátria das chuteiras" as mulheres não tem vez. In: Fazendo Gênero 7. Florianópolis, 2006. Anais eletrônicos... Florianópolis, 2006. Disponível em: <http://www. fazendogenero7.ufsc.br/artigos/S/Silvana_Vilodre_Goellner_21.pdf>. Acesso em: 6 nov. 2006.

GOMES, R. F. F.; CUNHA, B. B. B. Infância e diversidade: um estudo sobre as significações de gênero no brincar. Disponível em: <www.assis.unesp.br/.../65_RENATA_FERNANDES_ GOMES.pdf>. Acesso em: 20 out. 2011.

HALL, S. A centralidade da cultura: notas sobre as revoluções culturais do nosso tempo. In: THOMPSON, K. (Ed.). Media and cultural regulation. London, Thousand Oaks, New Delhi: The Open University; SAGE Publications, 1997.

LOURO, G. L. O corpo educado: pedagogias da sexualidade. Belo Horizonte: Autêntica, 2000. 2007.

. Gênero, sexualidade e educação: uma perspectiva pós-estruturalista. Petrópolis: Vozes,

NETO, O. C. et. al. Grupos focais e pesquisa social qualitativa: o debate orientado como técnica de investigação. XIII Encontro da Associação Brasileira de Estudos Populacionais, 2002, Ouro Preto. Anais eletrônicos... Ouro Preto, 2002. Disponível em: http://www.abep.nepo.unicamp. br/docs/anais/pdf/2002/Com_JUV_PO27_Neto_texto.pdf. Acesso em: 02 jun. 2012.

PENTEADO, C.; MENDONÇA, A. A identidade de gênero no jardim de infância - que construção social? In: Atas do V Colóquio CIE/DCE - Uma Pesquisar para Mudar (a Educação), 2009. Anais eletrônicos... 2009. Disponível em: http://www3.uma.pt/alicemendonca/ conteudo/publica/candidapenteado.pdf. Acesso em: 20 out. 2011.

PEREIRA, S. A. M.; MOURÃO, L. Identificações de gênero: jogando e brincando em universos divididos. Motriz, Rio Claro, v. 11 n. 3, p. 205-210, set./dez. 2005.

RELATÓRIO. Projeto Brincadeiras com meninos e meninas de e na rua. UEM, 2011.

RIBEIRO, J. S. B. Brincadeiras de meninas e meninos: socialização, sexualidade e gênero entre crianças e a construção social das diferenças. Cadernos Pagu, Campinas, v. 26, p. 145-168, jan./ jun. 2006.

SCOTT, J. Gênero: uma categoria útil de análise. Educação e Realidade, Porto Alegre, v. 20, n. 2, p. 71-100, jul./dez. 1995.

SILVA, L. I. C. et. al. Diferenças de Gêneros nos Grupos de Brincadeira na Rua: A Hipótese de Aproximação Unilateral. Psicologia: Reflexão \& Crítica, Porto Alegre, v. 19, n. 1, p. 114 $121,2004$.

STRAUB, J. L. Brincadeiras: práticas culturais de governo da criança. 2002.118 f. Dissertação (Mestrado) - Universidade Federal do Rio Grande do Sul, Programa de Pós-Graduação em Educação, Porto Alegre, 2002. 
WENETZ, I. Gênero e sexualidade nas brincadeiras do recreio. 2005. 203 f. Dissertação (Mestrado) - Universidade Federal do Rio Grande do Sul, Escola de Educação Física, Programa de Pós-Graduação em Movimento Humano, Porto Alegre, 2005.

Presentes na escola e ausentes na rua: brincadeiras de crianças marcadas pelo gênero e pela sexualidade. 2012. 231 f. Tese (Doutorado em Ciências do Movimento Humano) - Universidade Federal do Rio Grande do Sul, Escola de Educação Física, Programa de Pós-Graduação em Ciências do Movimento Humano, Porto Alegre, 2012.

WÜRDIG, R. C. O quebra-cabeça da cultura lúdica: lugares, parcerias e brincadeiras de crianças: desafios para políticas da infância. 2007. 229 f. Tese (doutorado) - Universidade do Vale do Rio dos Sinos, Programa de Pós-Graduação em Educação, 2007.

\section{Notas}

\footnotetext{
${ }^{1}$ Essa pesquisa compõe parte da pesquisa de Mestrado da autora, suscitando discussões específicas no que tange as questões de gênero, sexualidade e o brincar nas culturas infantis. Além dessas discussões, foram abordados temas específicos sobre a falta de formação docente para o trato com essa temática, além da problematização com relação à influência de determinadas Instituições como a Família e a Religião interferindo, direta ou indiretamente, na intervenção docente e na constituição das identidades.

${ }^{2}$ Trilhas da Diversidade foi um jogo de tabuleiro construído pelas autoras, com o fim específico de intervenção e formação, discutindo as temáticas de gênero e sexualidade em diferentes contextos, oferecendo a dinâmica de cartas com perguntas e respostas.

${ }^{3}$ Professoras e crianças foram identificadas com nomes fictícios visando preservar suas identidades e o sigilo ético na pesquisa. Além disso, suas falas foram postas em itálico no trabalho para melhor visualização.
}

* Doutoranda em Educação pela Universidade Estadual de Maringá, Maringá, Paraná, Brasil.

** Professora doutora da Universidade Estadual de Maringá, Maringá, Paraná, Brasil.

\section{Correspondência}

Cássia Cristina Furlan - Rua Luis Monteiro, 220, Jardim São Tomás, CEP: 86073-640 - Londrina, Paraná, Brasil.

E-mail: cassiacfurlan@gmail.com - veremuller@gmail.com

Recebido em 06 de maio de 2014

Aprovado em 07 de maio de 2015 